\title{
Education, Income, Wealth Inequality and Business Cycles in a General Equilibrium Growth Model
}

Wei-bin Zhang*

\section{Summary}

The paper is concerned with the dynamic interactions between physical capital, human capital, income and wealth inequalities between different households with government subsidy to education. It generalizes the endogenous growth model of a small-open economy proposed by Zhang (2016). Zhang's paper deals with income and wealth inequalities between heterogeneous households with government subsidy to education. The paper makes a contribution to the literature of economic growth with endogenous education by integrating Solow-Uzawa's neoclassical growth theory, Uzawa-Lucas model, Arrow's learning by doing, Zhang's creative leisure, and Walrasian general equilibrium theory. The model treats endogenous capital and human capital accumulation as the main engines of economic growth. This study generalizes Zhang's model by allowing constant coefficients to be timedependent. We simulate the generalized model to demonstrate existence of business cycles due to various exogenous periodic shocks.

Keywords: business cycles; income and wealth distribution; heterogeneous household

JEL: 041, E32

\section{Introduction}

This paper is concerned with dynamic relationships between economic growth and income and wealth inequalities. Forbes (2000) argued for the necessity of a new analytical framework as follows: "careful reassessment of the relationship between these two variables (growth rate and income inequality) needs further theoretical and empirical work evaluating the channels through which inequality, growth, and any other variables are related." This study emphasizes the role of government subsidy policy on human capital and inequalities. It generalizes the endogenous growth model of a small-open economy proposed by Zhang (2016). Zhang's paper studies dynamic interactions between human capital and physical capital within a general equilibrium framework. It examines the role of government subsidy policy on human capital and inequalities. It also deals with income and wealth inequalities between heterogeneous households with government subsidy to education. It makes a contribution to the literature of economic growth with endogenous education by integrating Solow-Uzawa's neoclassical growth theory (Solow, 1956; Uzawa, 1961), Uzawa-Lucas model (Uzawa, 1965; Lucas, 1988), Arrow's learning by doing (Arrow, 1962), Zhang's creative leisure (Zhang,

\footnotetext{
1 1-1 Jumonjibaru 1-1 Jumonjibaru Beppu-shi Oita-ken 874-8577 Japan
} 


\section{Articles}

2007), and Walrasian general equilibrium theory (Walras, 1874; Arrow and Debreu, 1954; Arrow and Hahn, 1971; and Mas-Colell et al., 1995). The model treats endogenous capital and human capital accumulation as the main engines of economic growth. It is influenced by the literature of growth and trade of small open-economies (e.g., Obstfeld and Rogoff, 1996; Galí and Monacelli, 2005). This study generalizes Zhang's model by allowing constant coefficients to be time dependent. We simulate the generalized model to demonstrate existence of business cycles due to various exogenous periodic shocks. There are many economic models which exhibit business cycles due to different mechanisms (Zhang 1991, 2005, 2006; Lorenz 1993; Chiarella and Flaschel 2000; Shone 2002; Gandolfo 2005; Puu 2011; Stachurski, et al. 2014; and Nolte, 2015). These studies demonstrate how modern dynamic analysis can be applied to different economic systems by exposing the existence of cycles, regular as well as irregular oscillations, and chaos in economic systems. There are also other research papers which identify economic business cycles from different perspectives. Lucas (1977) introduced different exogenous shocks which affect all sectors and cause business cycles. Chatterjee and Ravikumar (1992) introduce seasonal perturbations to taste and technology to a neoclassical growth model. They show how the seasonal demand and supply perturbations cause aggregated cycles. Gabaix (2011) use uncorrelated sectoral shocks as determinants of aggregate fluctuations (see also, Giovanni, et al. 2014; Stella, 2015). This study contributes to the literature of business cycles by showing periodic oscillations in a general equilibrium model with endogenous human capital wealth.

In Section 2 we generalize Zhang's small open growth model of endogenous wealth and human capital accumulation. In Section 3 we examine properties of the dynamic model
Education, Income, Wealth Inequality and Business

Cycles in a General Equilibrium Growth Model

and simulate the model when all coefficients are time-independent. In Section 4 we simulate the model to show the existence of business cycles with different time-dependent shocks. In Section 5 we conclude the study. The results of Section 3 are checked in the Appendix.

\section{The basic model}

We refer to Zhang $(2013,2016,2020)$ for modelling economic structure, wealth and human capital accumulation, and government's taxation. Most aspects of the production sectors are built on the basis of neoclassical growth theory. The economy of production side consists of capital goods, consumer good and education sectors. The three sectors are perfectly competitive and are taxed by the government. The tax income is fully expended on subsidizing students. Assets of the economy belong to households. The households' incomes are distributed to consume and to save. Saving is carried out only by households. Firms employ labor and physical capital inputs to produce goods and services. All markets are perfectly competitive. Input factors are always fully employed. All earnings of firms are paid to factors of production, labor, managerial skill and capital ownership. The population is groped into $J$ groups, indexed by $j=1, \ldots, J$. We measure prices in terms of the commodity. The price of the commodity be unit. As the economy is small, the rate of interest $r^{*}(t)$ is determined in global markets. We introduce variables as follows:

subscript index $i, s$ and $e-$ capital goods sector, consumer goods

sector, and education sector;

$N_{m}(t)$ and $K_{m}(t)$ - labor force and capital stocks employed by sector $m=i, s, e$ at $t$;

$F_{m}(t)$ - the production function of sector $m$; 


\section{Articles}

$p_{s}(t)$ and $p_{e}(t)$ - the price of consumer good and the price of education per unit of time;

$\tau(t)$ and $\bar{\tau}(t)$ - the tax rate on each sector and $\bar{\tau}(t) \equiv 1-\tau(t)$;

$K(t)$ and $\bar{K}(t)$ - physical capital employed by and wealth owned by the country;

$\bar{N}_{j}(t)$ and $H_{j}(t)$ - group $j$ 's population and level of human capital;

$T_{j}(t), \bar{T}_{j}(t)$ and $T_{j e}(t)$ - the work time, leisure time, and study time of a typical worker in group $j$;

$w_{j}(t)$ and $\bar{k}_{j}(t)-$ group $j$ 's wage and per capita wealth of group $j$;

$\delta_{k}(t)$ and $r_{0}(t)$ - depreciation rate of capital and $r_{0}(t) \equiv r^{*}(t)+\delta_{k}(t)$.

The labor service is $T_{j}(t) H_{j}^{m_{j}(t)}(t)$ where we call $m_{j}(t)$ utilization efficiency of human capital by group $j$. The total labor input by a group is the sum of labor inputs of the group population, $T_{j}(t) H_{j}^{m_{j}(t)}(t) \bar{N}_{j}(t)$. The total labor input $N(t)$ is:

$$
\begin{aligned}
N(t) & =\sum_{j=1}^{J} T_{j}(t) H_{j}^{m_{j}(t)}(t) \bar{N}_{j}(t), \\
j & =1, \ldots, J .
\end{aligned}
$$

\section{Full employment of input factors}

Full employment of the labor force implies: $N_{i}(t)+N_{s}(t)+N_{e}(t)=N(t)$.

The national capital is fully employed

$K_{i}(t)+K_{s}(t)+K_{e}(t)=K(t)$.

\section{National wealth owned the population}

The national wealth is given by:

$\bar{K}(t)=\sum_{j=1}^{J} \bar{k}_{j}(t) \bar{N}_{j}(t)$.

\section{The capital goods sector}

The production function of the capital goods sector takes on the following form:

$$
\begin{gathered}
F_{i}(t)=A_{i}(t) K_{i}^{\alpha_{i}(t)}(t) N_{i}^{\beta_{i}(t)}(t), \\
\alpha_{i}(t), \beta_{i}(t)>0, \\
\alpha_{i}(t)+\beta_{i}(t)=1,
\end{gathered}
$$

in which $A_{i}(t), \alpha_{i}(t)$ and $\beta_{i}(t)$ are positive parameters. The marginal conditions are:

$r_{0}(t)=\frac{\alpha_{i}(t) \bar{\tau}(t) F_{i}(t)}{K_{i}(t)}$
$w(t)=\frac{\beta_{i}(t) \bar{\tau}(t) F_{i}(t)}{N_{i}(t)}$.

\section{The consumer goods sector}

The production function of the consumer goods sector is specified as:

$F_{S}(t)=A_{S}(t) K_{S}^{\alpha_{s}(t)}(t) N_{S}^{\beta_{s}(t)}(t)$,

$\alpha_{s}(t)+\beta_{S}(t)=1, \alpha_{s}(t), \beta_{s}(t)>0$,

in which $A_{s}(t), \alpha_{s}(t)$, and $\beta_{s}(t)$ are technological parameters. The marginal conditions imply:

$r_{0}(t)=\frac{\alpha_{s}(t) \bar{\tau}(t) p_{s}(t) F_{s}(t)}{K_{s}(t)}$,
$w(t)=\frac{\beta_{s}(t) \bar{\tau}(t) p_{s}(t) F_{s}(t)}{N_{s}(t)}$.

\section{The education sector}

We specify the production function of the education sector as:

$F_{e}(t)=A_{e}(t) K_{e}^{\alpha_{e}(t)}(t) N_{e}^{\beta_{e}(t)}(t)$,

$\alpha_{e}(t), \beta_{e}(t)>0, \alpha_{e}(t)+\beta_{e}(t)=1$,

in which $A_{e}(t), \alpha_{e}(t)$ and $\beta_{e}(t)$ are positive parameters. The marginal conditions are:

$r_{0}(t)=\frac{\alpha_{e}(t) \bar{\tau}(t) p_{e}(t) F_{e}(t)}{K_{e}(t)}$,
$w(t)=\frac{\beta_{e}(t) \bar{\tau}(t) p_{e}(t) F_{e}(t)}{N_{e}(t)}$. 


\section{Articles}

\section{Current and disposable incomes}

Household $j$ 's wage rate is given by:

$$
\begin{aligned}
& w_{j}(t)=w(t) H_{j}^{m_{j}(t)}(t), j=1, \cdots, J . \\
& y_{j}(t)=r^{*}(t) \bar{k}_{j}(t)+T_{j}(t) w_{j}(t) .
\end{aligned}
$$

Per capita current income from interest payment and wage payment is:

$y_{j}(t)=r^{*}(t) \bar{k}_{j}(t)+T_{j}(t) w_{j}(t)$.

Per household's disposable income is:

$$
\hat{y}_{j}(t)=y_{j}(t)+\bar{k}_{j}(t)=
$$$$
\left(1+r^{*}(t)\right) \bar{k}_{j}(t)+T_{j}(t) w_{j}(t) \text {. }
$$

The disposable income is used up for saving $s_{j}(t)$, consumer goods $c_{s j}(t)$ and education $T_{e j}(t)$. As household $j$ receives $\tau_{j}(t)$ units of subsidy per unit of time from the government. The education cost is the education price charged by the education sector minus the subsidy from the government: $\bar{p}_{j}(t)=p_{e}(t)-\tau_{j}(t)$.

We have the budget constraint $p_{s}(t) c_{s j}(t)+\bar{p}_{j}(t) T_{e j}(t)+s_{j}(t)=$ $=\hat{y}_{j}(t)=\left(1+r^{*}(t)\right) \bar{k}_{j}(t)+T_{j}(t) w_{j}(t)$.

The time available $T_{0}$ is fully spent on working, leisure and education:

$$
\begin{aligned}
& T_{j}(t)+\bar{T}_{j}(t)+T_{e j}(t)=T_{0} . \\
& \quad \text { Insert (14) in (13): } \\
& p_{s}(t) c_{s j}(t)+p_{e j}(t) T_{e j}(t)+ \\
& \quad+w_{j}(t) \bar{T}_{j}(t)+s_{j}(t)=\bar{y}_{j}(t) \\
& \quad \text { in which } \\
& p_{e j}(t) \equiv \bar{p}_{j}(t)+w_{j}(t), \bar{y}_{j}(t) \equiv \\
& \quad \equiv\left(1+r^{*}(t)\right) \bar{k}_{j}(t)+w_{j}(t) T_{0} .
\end{aligned}
$$

\section{Utility function and optimal decision}

The utility function is related to $T_{e j}(t)$, $\bar{T}_{j}(t), c_{s j}(t)$, and $s_{j}(t)$ as follows:

$$
\begin{gathered}
U_{j}(t)=T_{e j}^{\kappa_{0 j}(t)}(t) \bar{T}^{\sigma_{0 j}(t)}(t) c_{s j}^{\xi_{0 j}(t)}(t) s_{j}^{\lambda_{0 j}(t)}(t), \\
\kappa_{0 j}(t), \sigma_{0 j}(t), \xi_{0 j}(t), \lambda_{0 j}(t)>0,
\end{gathered}
$$

in which $\kappa_{0 j}(t), \sigma_{0 j}(t), \xi_{0 j}(t)$, and $\lambda_{0 j}(t)$ are propensity to receive education, to enjoy
Education, Income, Wealth Inequality and Business

Cycles in a General Equilibrium Growth Model

leisure, to consume consumer good, and to hold wealth, respectively.

Maximize $U_{j}(t)$ subject to (15)

$p_{e j}(t) T_{e j}(t)=\kappa_{j}(t) \bar{y}_{j}(t)$,

$w_{j}(t) \bar{T}_{j}(t)=\sigma_{j}(t) \bar{y}_{j}(t)$,

$p_{s}(t) c_{s j}(t)=\xi_{j}(t) \bar{y}_{j}(t)$,

$s_{j}(t)=\lambda_{j}(t) \bar{y}_{j}(t)$,

where

$$
\begin{aligned}
\kappa_{j}(t) & \equiv \kappa_{0 j}(t) \rho_{j}(t), \\
\sigma_{j}(t) & \equiv \sigma_{0 j}(t) \rho_{j}(t), \\
\xi_{j}(t) & \equiv \xi_{0 j}(t) \rho_{j}(t), \\
\lambda_{j}(t) & \equiv \lambda_{0 j}(t) \rho_{j}(t), \\
\rho_{j}(t) & \equiv \frac{1}{\kappa_{0 j}(t)+\sigma_{0 j}(t)+\xi_{0 j}(t)+\lambda_{0 j}(t)} .
\end{aligned}
$$

\section{Change in the household wealth}

The change in wealth is savings minus dissaving:

$\dot{\bar{k}}_{j}(t)=s_{j}(t)-\bar{k}_{j}(t)$.

\section{Dynamics of human capital}

We assume three sources of human capital accumulation: learning by producing (Arrow, 1962), learning through formal education (Uzawa, 1965), and creative leisure (Zhang, 2007). Human capital accumulation is thus given by

$$
\begin{aligned}
\dot{H}_{j}(t) & =\frac{v_{e j}(t)\left(F_{e}(t) / N_{e}(t)\right)^{a_{e j}(t)}\left(H_{j}^{m_{j}(t)}(t) T_{e j}(t)\right)^{b_{e j}(t)}}{H_{j}^{\pi_{e j}}(t)}+ \\
& +\frac{v_{i j}(t)\left(F_{i}(t) / N_{i}(t)\right)^{a_{i j}(t)}}{H_{j}^{\pi_{i j}(t)}(t)} \\
& +\frac{v_{h j}(t) c_{s j}^{a_{h j}(t)}(t)}{H_{j}^{\pi_{h j}(t)}(t)}-\delta_{h j}(t) H_{j}(t),
\end{aligned}
$$

where $\delta_{h j}(t)(>0)$ are depreciation rates of human capital, $v_{e j}(t), v_{i j}(t), v_{h j}(t)$, $a_{e j}(t), b_{e j}(t), a_{i j}(t)$, and $a_{h j}(t)$ are nonnegative parameters. We use $\pi_{e j}(t), \pi_{i j}(t)$, 


\section{Articles}

and $\pi_{h j}(t)$ to measure returns to scale in human capital accumulation. For instance, if $\pi_{e j}(t)>0(=0,<0)$, we say that group 1's human capital accumulation due to education exhibits decreasing (neutral, increasing) returns to scale. We don't specify the signs of the parameters $\pi_{e j}(t), \pi_{i j}(t)$, and $\pi_{h j}(t)$ in this stage of modelling.

\section{Demand of and supply for consumer goods}

Equilibrium in consumer goods market implies

$\sum_{j=1}^{J} c_{s j}(t) \bar{N}_{j}(t)=F_{S}(t)$.

\section{Demand of and supply for education}

Equilibrium in education markets implies

$\sum_{j=1}^{J} T_{e j}(t) \bar{N}_{j}(t)=F_{e j}(t)$.

\section{The government budget}

The subsidies which the students receive equals the government's tax income

$$
\begin{gathered}
\sum_{j=1}^{J} \tau_{j} T_{e j}(t) \bar{N}_{j}(t)=\tau(t)\left(F_{i}(t)+\right. \\
\left.+p_{S}(t) F_{S}(t)+p_{e}(t) F_{S}(t)\right) .
\end{gathered}
$$

We completed the model. The modelling structure is general as some well-known models are its special cases (Solow, 1956; Uzawa, 1961; Samuelson, 1959; and Pasinetti, 1960).

\section{The Dynamic Properties of the Model}

We build a model for an economy which has any number of households and three production sectors. The model is generally very complicated. Before stating a lemma for describina dvnamics. we introduce $\left\{\bar{k}_{j}(t)\right\} \equiv\left(\bar{k}_{2}(t), \cdots, \bar{k}_{J}(t)\right)$,
$\left(H_{j}(t)\right) \equiv\left(H_{1}(t), \cdots, H_{J}(t)\right)$.

\section{Lemma}

The dynamics of the economy with $J$ types of households is governed by the following $2 J$ dimensional differential equations with $\tau(t)$, $\left\{\bar{k}_{j}(t)\right\},\left(H_{j}(t)\right)$, and $t$ as variables

$\dot{\tau}(t)=\Lambda_{1}\left(\tau(t),\left(H_{j}(t)\right),\left\{\bar{k}_{j}(t)\right\}, t\right)$,

$\dot{\bar{k}}_{j}(t)=\Lambda_{j}\left(\tau(t),\left(H_{j}(t)\right),\left\{\bar{k}_{j}(t)\right\}, t\right), \quad j=2, \ldots, J$,

$\dot{H}_{j}(t)=\Omega_{j}\left(\tau(t),\left(H_{j}(t)\right),\left\{\bar{k}_{j}(t)\right\}, t\right), \quad j=1, \ldots, J$,

in which $\Lambda_{j}$ and $\Omega_{j}$ are unique functions of $\tau(t),\left\{\bar{k}_{j}(t)\right\},\left(H_{j}(t)\right)$, and $t$ defined in the Appendix. We decide other variables as functions of $\tau(t),\left\{\bar{k}_{j}(t)\right\},\left(H_{j}(t)\right)$, and $t$ as follows: $\bar{\tau}(t)=1-\tau(t) \rightarrow w(t)$ by $(\mathrm{A} 3) \rightarrow$ $w_{j}(t)$ by (A4) $\rightarrow p_{s}(t)$ by (A5) $\rightarrow p_{e}(t)$ by $(\mathrm{A} 6) \rightarrow \bar{k}_{1}(t)$ by $(\mathrm{A} 18) \rightarrow N_{i}(t)$ by $(\mathrm{A} 15) \rightarrow$ $N_{e}(t)$ by $(\mathrm{A} 11) \rightarrow N_{s}(t)$ by $(\mathrm{A} 9) \rightarrow \bar{y}_{j}(t)$ by $(\mathrm{A} 7) \rightarrow T_{j}(t)$ by $(\mathrm{A} 12) \rightarrow N(t)$ by $(2) \rightarrow$ $K_{m}(t), j=i, s, e$, by (A1) $\rightarrow F_{m}(t)$ by the definitions $\rightarrow \bar{T}_{j}(t), T_{e j}(t), c_{j}(t)$, and $s_{j}(t)$ by (16) $\rightarrow K(t)$ by (3) $\rightarrow \bar{K}(t)$ by (4).

The Lemma provides a computational program to simulate the motion of the dynamic system with computer. The rest of this section is based on Zhang (2016). We simulate a 3-group economy with the following parameter values as follows

$$
\begin{aligned}
& \left(\begin{array}{l}
\tau_{1} \\
\tau_{2} \\
\tau_{3}
\end{array}\right)=\left(\begin{array}{c}
0 \\
0.2 \\
0.4
\end{array}\right),\left(\begin{array}{l}
N_{1} \\
N_{2} \\
N_{3}
\end{array}\right)=\left(\begin{array}{c}
1 \\
69 \\
20
\end{array}\right),\left(\begin{array}{l}
m_{1} \\
m_{2} \\
m_{3}
\end{array}\right)=\left(\begin{array}{c}
0.7 \\
0.15 \\
0.1
\end{array}\right), \\
& \left(\begin{array}{l}
\xi_{10} \\
\xi_{20} \\
\xi_{30}
\end{array}\right)=\left(\begin{array}{c}
0.07 \\
0.18 \\
0.2
\end{array}\right),\left(\begin{array}{l}
\lambda_{10} \\
\lambda_{20} \\
\lambda_{30}
\end{array}\right)=\left(\begin{array}{c}
0.9 \\
0.65 \\
0.6
\end{array}\right),\left(\begin{array}{c}
\sigma_{10} \\
\sigma_{20} \\
\sigma_{30}
\end{array}\right)=\left(\begin{array}{c}
0.14 \\
0.2 \\
0.2
\end{array}\right), \\
& \left(\begin{array}{l}
\kappa_{10} \\
\kappa_{20} \\
\kappa_{30}
\end{array}\right)=\left(\begin{array}{c}
0.03 \\
0.02 \\
0.02
\end{array}\right),\left(\begin{array}{l}
v_{e 1} \\
v_{e 2} \\
v_{e 3}
\end{array}\right)=\left(\begin{array}{c}
0.8 \\
0.7 \\
0.6
\end{array}\right),\left(\begin{array}{l}
a_{e 1} \\
a_{e 2} \\
a_{e 3}
\end{array}\right)=\left(\begin{array}{c}
0.3 \\
0.25 \\
0.2
\end{array}\right), \\
& \left(\begin{array}{l}
b_{e 1} \\
b_{e 2} \\
b_{e 3}
\end{array}\right)=\left(\begin{array}{c}
0.2 \\
0.15 \\
0.1
\end{array}\right),\left(\begin{array}{c}
v_{i 1} \\
v_{i 2} \\
v_{i 3}
\end{array}\right)=\left(\begin{array}{c}
0.2 \\
0.15 \\
0.1
\end{array}\right),\left(\begin{array}{c}
a_{i 1} \\
a_{i 2} \\
a_{i 3}
\end{array}\right)=\left(\begin{array}{c}
0.2 \\
0.15 \\
0.1
\end{array}\right), \\
& \left(\begin{array}{c}
v_{h 1} \\
v_{h 2} \\
v_{h 3}
\end{array}\right)=\left(\begin{array}{c}
0.2 \\
0.15 \\
0.1
\end{array}\right),\left(\begin{array}{l}
a_{h 1} \\
a_{h 2} \\
a_{h 3}
\end{array}\right)=\left(\begin{array}{c}
0.2 \\
0.15 \\
0.1
\end{array}\right),\left(\begin{array}{c}
\delta_{h 1} \\
\delta_{h 2} \\
\delta_{h 3}
\end{array}\right)=\left(\begin{array}{c}
0.04 \\
0.06 \\
0.08
\end{array}\right),
\end{aligned}
$$




\section{Articles}

$r^{*}=0.053, A_{i}=1, A_{s}=0.9, A_{e}=0.7$,

$\alpha_{i}=0.32, \alpha_{s}=0.34, \alpha_{e}=0.33, T_{0}=24$,

$\delta_{k}=0.05, \pi_{m 1}=0.2, \pi_{m 2}=0.4, \pi_{m 3}=0.5$,

$m=e, i, h$. (22)

The initial conditions are:

$\tau(0)=0.007, \bar{k}_{2}(0)=66, \bar{k}_{3}(0)=50$,

$H_{1}(0)=32, H_{2}(0)=9, H_{3}(0)=5$.
Education, Income, Wealth Inequality and Business

Cycles in a General Equilibrium Growth Model

Figure 1 describes the motion of the system. It should be noted that all the figures in the paper are based on (22) and (23) without referring to any real economy. The national output $Y$ in Figure 1 is:

$Y(t)=F_{i}(t)+p_{s}(t) F_{s}(t)+p_{e}(t) F_{e}(t)$.
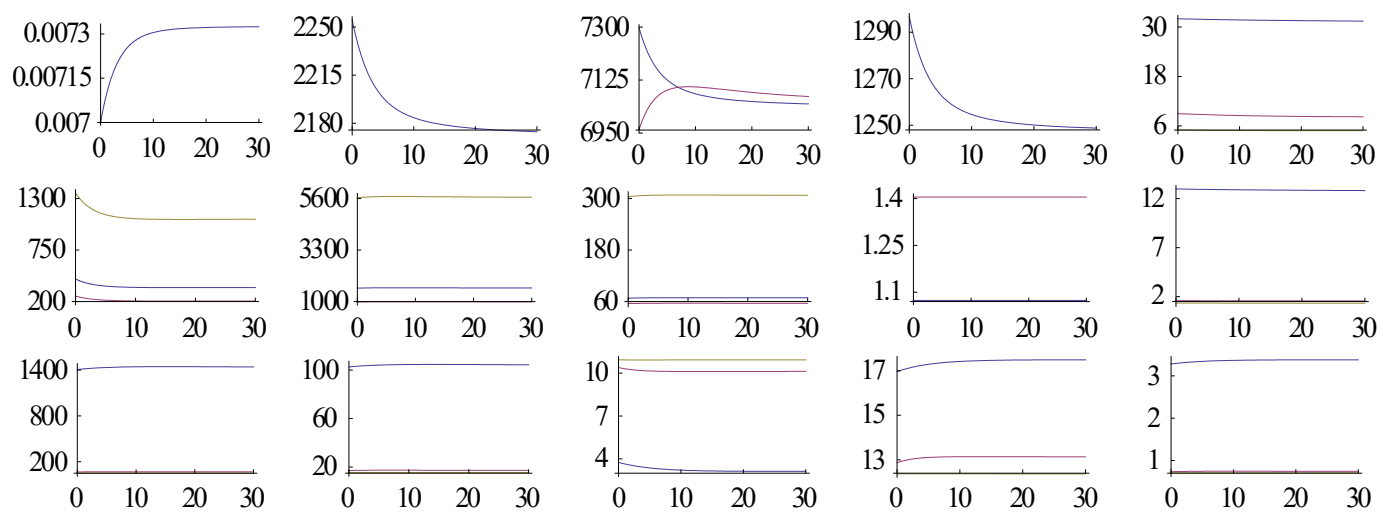

Figure 1. The Motion of the Economic System

The system has an equilibrium point as given in (24):

$\tau=0.0073, Y=2172.4, K=7041.4$,

$\bar{K}=7053.8 . N=1248, F_{i}=351.4$,

$F_{S}=1605.6, F_{e}=68.8, K_{i}=1083.8$,

$K_{s}=5650.2, K_{e}=307.4, N_{i}=206.8$,

$N_{s}=985, N_{e}=56, p_{s}=1.07, p_{e}=1.41$,

$w_{1}=12.75, w_{2}=1.57, w_{3}=1.34$,

$H_{1}=31.2, H_{7}=8.15, H_{3}=4.83$,

$\bar{k}_{1}=1432, \bar{k}_{2}=67, \bar{k}_{3}=49.8$,

$c_{S 1}=103.7, c_{S 2}=17.3, c_{S 3}=15.5$,

$T_{1}=3.16, T_{2}=10.1, T_{3}=10.9$,

$\bar{T}_{1}=17.5, \bar{T}_{2}=13.1, \bar{T}_{3}=12.4$,

$T_{e 1}=3.4, T_{e 2}=0.74, T_{e 3}=0.71$.

The six eigenvalues as follows:

$-0.38,-0.35,-0.18,-0.12,-0.08,-0.04$

The negative real eigenvalues guarantees that we can safely conduct comparative dynamic analysis.

\section{Comparative Dynamic Analysis}

The previous section generalized Zhang's model. We also reported the simulation results by Zhang. This section shows existence of business cycles when the system is subject to periodic perturbations. We use a variable $\bar{\Delta} x_{j}(t)$ to represent for the change rate of the variable $x_{j}(t)$ in percentage due to the change in a parameter.

\subsection{The subsidy of education to the poor changes periodically}

First, we study effects of the change in the subsidy of education to the poor on the economy. It has been argued that the subsidy of education explains much of economic growth. We see what will happen to the economy when the subsidy of education experiences the following fluctuations:

$$
\tau_{3}(t)=0.4+0.02 \sin (t) .
$$

The simulation result is plotted in Figure 2. As the system contains many variables and these variables are connected to each other in nonlinear relations, it is difficult to verbally explain these interactions over time. As the subsidy of education to the poor is fluctuated, 


\section{Articles}

the output levels of the three sectors are variables of the system also oscillate over oscillatory. The human capital level of the poor is relatively strongly affected. The rest time.
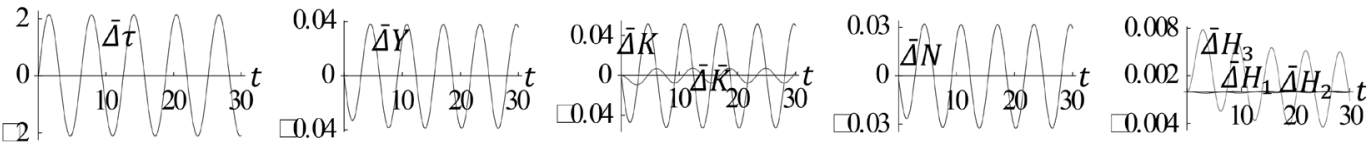

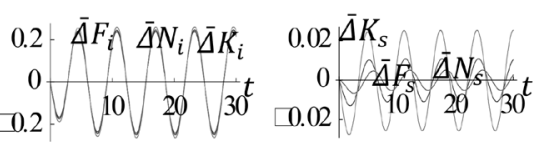
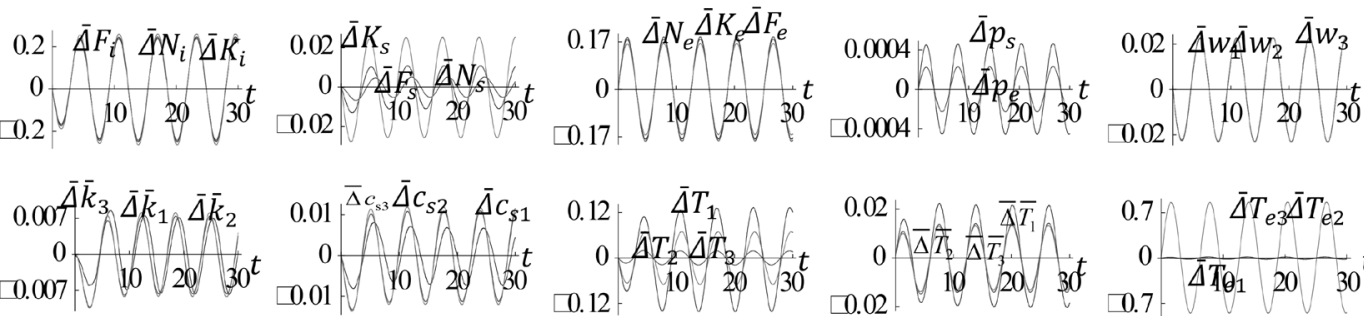

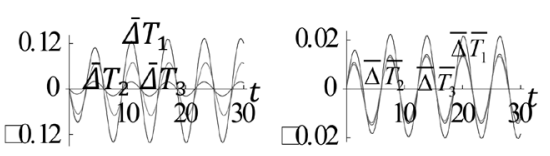

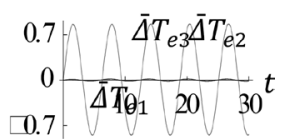

Figure 2. The Subsidy of Education to the Poor Oscillates Periodically

\subsection{The rich's propensity to receive education oscillates periodically}

We now examine a case that the rich's propensity to receive education oscillates periodically as follows:

$\kappa_{01}(t)=0.03+0.005 \sin (t)$

We plot the simulation results in Figure 3.

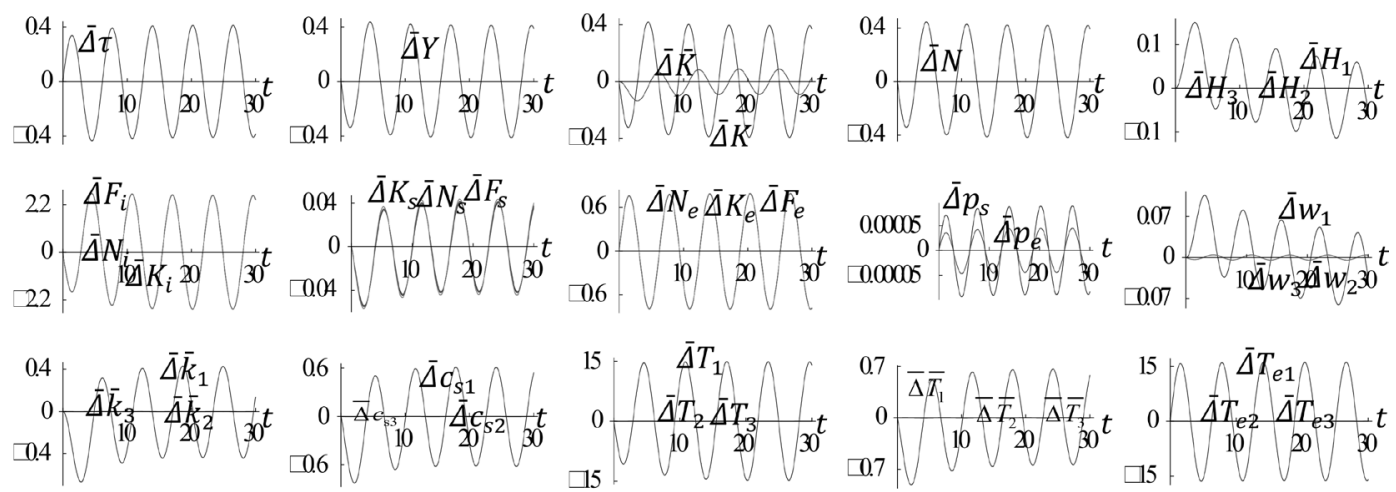

Figure 3. The Rich's Propensity to Receive Education Oscillates Periodically

\subsection{The rich's propensity to enjoy leisure oscillates periodically}

We now study a case that the rich's propensity to enjoy leisure oscillates periodically as follows:

$\sigma_{10}(t)=0.14+0.02 \sin (t)$.

The simulation results are plotted in Figure 4. 


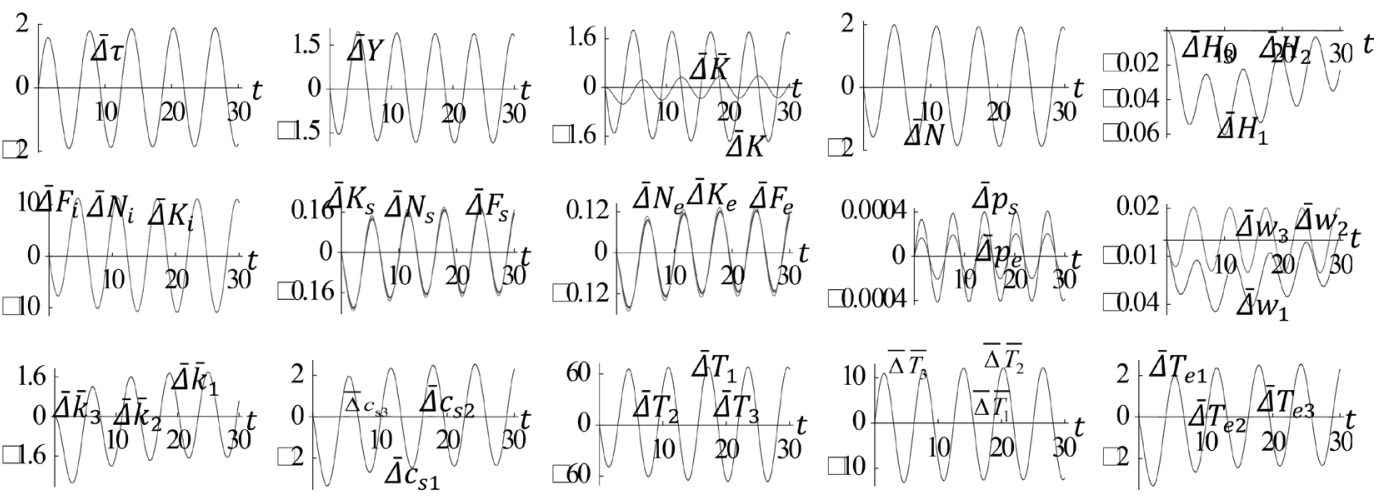

Figure 4. The Rich's Propensity to Enjoy Leisure Oscillates Periodically

\subsection{The poor's population oscillates periodically}

We now allow the poor's population to oscillate periodically as follows:

$$
\bar{N}_{3}(t)=20+\sin (t)
$$

The simulation results are plotted in Figure 5.
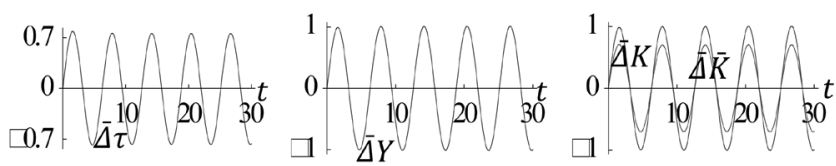

\begin{tabular}{c|c|cc|c}
1 & $\bar{\Delta} F_{i}$ & $\bar{\Delta} N_{i}$ & $\hat{\Delta} K_{\dot{f}}$ & \\
0 & & 10 & 20 & 30
\end{tabular}

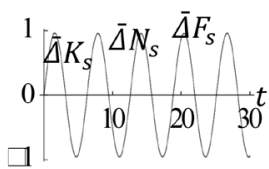

$0.003 \bar{\Delta} \bar{k}_{1} \overline{4} \bar{k}_{2} \bar{\Delta} \bar{k}_{3}$ $0.003+\sqrt{10} \sqrt{20}(30$ 0.004 $0.004 \Delta c_{s} \bar{\Delta} c_{s 2} \Delta c_{s 3}$
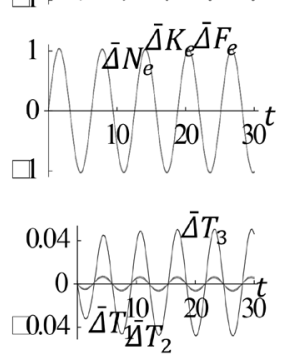

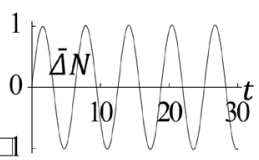

0.00002 $0.00002 \bar{H} H_{310} \sqrt{20} 30$ $0.0000 € \bar{\Delta} \mathrm{H}_{\mathrm{P}} \mathrm{H}_{2}$

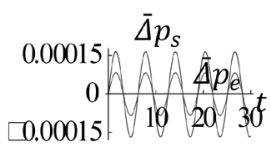

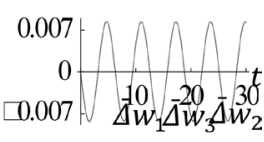

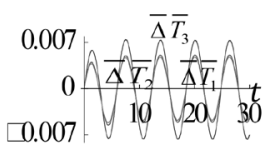

$0.006{ }^{\bar{\Delta}} T_{\rho 3}$ 0.006 . 10 . 20 30

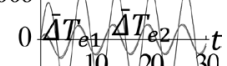

Figure 5. The Poor's Population Oscillates Periodically

\subsection{The poor's human capital utilization} efficiency oscillates periodically

We now examine what happen to the economic system if the poor's human capital utilization efficiency oscillates periodically as follows:

$$
m_{1}(t)=0.1+0.01 \sin (t) .
$$

The simulation results are plotted in Figure 6. 


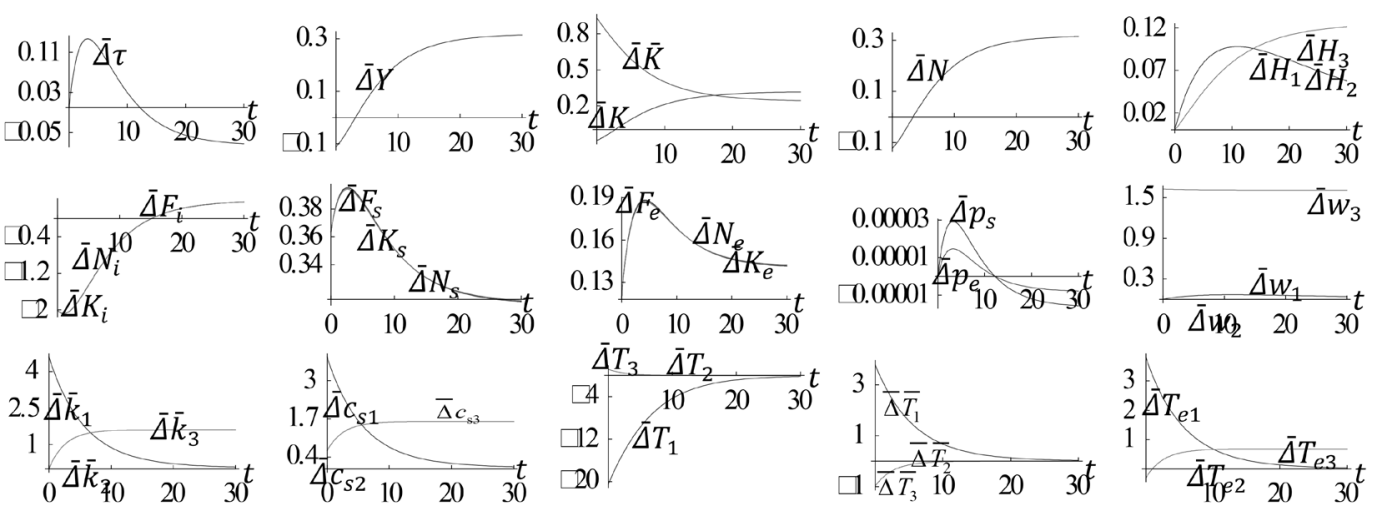

Figure 6. The Poor's Human Capital Utilization Efficiency Oscillates Periodically

\section{Concluding Remarks}

This paper proposed an endogenous growth model of a small-open economy. The paper dealt with dynamic interactions between physical capital, human capital, income and wealth inequalities between different households with government subsidy to education. We emphasized the role of government education. The model of heterogeneous households was developed on the basis of Solow-Uzawa's neoclassical growth theory, Uzawa-Lucas model, Arrow's learning by doing, Zhang's creative leisure, and Walrasian general equilibrium theory. The model treats capital and human capital accumulation as endogenous. The capital accumulation and economic structure are based on the neoclassical growth theory. The human capital accumulation is due to Uzawa's education, Arrow's learning by doing, and Zhang's creative leisure. The paper generalized the endogenous growth model of a small-open economy proposed by Zhang (2016). Zhang's paper studies dynamic interactions between human capital and physical capital within a general equilibrium framework. It also deals with income and wealth inequalities between heterogeneous households with government subsidy to education. The paper makes a contribution to the literature of economic growth with endogenous education by integrating SolowUzawa's neoclassical growth theory, UzawaLucas model, Arrow's learning by doing, Zhang's creative leisure, and Walrasian general equilibrium theory. It considers endogenous capital and human capital accumulation as the main engines of economic growth. This study generalized Zhang's model by allowing constant coefficients to be timedependent. After making the generalization, we simulated the model to demonstrate existence of business cycles due to various exogenous periodic shocks. The model can be generalized and extended in different directions. It has many limitations when one thinks of the literature of different branches of economics. For instance, social mobility is neglected. Moreover, a government may affect distribution and growth in many different ways. We may also get more insights by allowing multiple parameters to oscillate simultaneously. 


\section{Articles}

\section{Appendix: Proving the Lemma}

$z \equiv \frac{r_{0}}{w}=\frac{N_{m}}{\bar{\beta}_{m} K_{m}}, m$

$$
=i, s, e \text {, (A1) }
$$

in which $\bar{\beta}_{m} \equiv \beta_{m} / \alpha_{m}$. From (A1) and (3), we have:

$\frac{N_{i}}{\bar{\beta}_{i}}+\frac{N_{s}}{\bar{\beta}_{s}}+\frac{N_{e}}{\bar{\beta}_{e}}=z K$.

Substitute (A1) into (6):

$$
\begin{aligned}
z= & \left(\frac{r_{0}}{\alpha_{i} \bar{\tau} A_{i}}\right)^{1 / \beta_{i}} \frac{1}{\bar{\beta}_{i}}, w(z) \\
=\alpha z^{-\alpha_{i}}, & \text { (A3) }
\end{aligned}
$$

in which $\alpha=\beta_{i} \bar{\tau} A_{i} \bar{\beta}_{i}^{-\alpha_{i}}$. We have:

$w_{j}\left(H_{j}, z\right)=H_{j}^{m_{j}} w$.

By (7) and (8), we obtain:

$p_{s}(z)=\frac{\bar{\beta}_{s}^{\alpha_{s}} z^{\alpha_{s}} w}{\beta_{s} \bar{\tau} A_{s}}$.

With (9) and (10), we get

$p_{e}(z)=\frac{\bar{\beta}_{e}^{\alpha_{e}} w z^{\alpha_{e}}}{\beta_{e} \bar{\tau} A_{e}}$.

By (A4) and the definitions of $\bar{y}_{j}$, we derive:

$\bar{y}_{j}=(1+r) \bar{k}_{j}+T_{0} w_{j}$. (A7)

Substitute $p_{s} c_{j}=\xi_{j} \bar{y}_{j}$ into (18):

$\sum_{j=1}^{J} \xi_{j} \quad \bar{N}_{j} \bar{y}_{j}=p_{s} F_{s}$.

From (A7) and (A8), we have

$N_{s}=\bar{\tau}\left(\sum_{j=1}^{J} \tilde{g}_{j} \bar{k}_{j}+\tilde{g}\right)$,

where we use $p_{s} F_{s}=w N_{s} / \bar{\tau} \beta_{s}$ and

From (16) and (20), we have

$\tilde{g}_{j}(z) \equiv \bar{r} \beta_{s} \xi_{j} \bar{N}_{j}, \bar{r}(z) \equiv \frac{1+r^{*}}{w}$,

$\tilde{g}\left(z,\left(H_{j}\right)\right) \equiv \beta_{S} T_{0} \sum_{j=1}^{J} H_{j}^{m_{j}} \xi_{j} \bar{N}_{j}$.
Education, Income, Wealth Inequality and Business

Cycles in a General Equilibrium Growth Model

in which we apply $F_{e}=w N_{e} / \bar{\tau} \beta_{e} p_{e}$. Insert (A7) in (A10)

$N_{e}=\bar{\tau}\left(\sum_{j=1}^{J} \bar{g}_{j} \bar{k}_{j}+\bar{g}\right)$,

in which

$\bar{g}_{j}=\frac{(1+r) \beta_{e} p_{e}}{w} \frac{\kappa_{j} \bar{N}_{j}}{p_{e j}}$,

$\bar{g} \equiv \frac{\beta_{e} T_{0} p_{e}}{w} \sum_{j=1}^{J} \frac{\kappa_{j} \bar{N}_{j} w_{j}}{p_{e j}}$.

Substitute (14) into (16):

$T_{j}=T_{0}-\tilde{p}_{e j} \bar{y}_{j}$,

in which

$\tilde{p}_{e j} \equiv \frac{\sigma_{j}}{w_{j}}+\frac{\kappa_{j}}{p_{e j}}$.

Substitute (A6) into (A12):

$T_{j}=\tilde{p}_{j}-(1+r) \bar{k}_{j} \tilde{p}_{e j}$,

in which

$\tilde{p}_{j}=T_{0}-T_{0} \tilde{p}_{e j} w_{j}$.

From (A13) in (1), we get

$N=n_{0}-\sum_{j=1}^{J} n_{j} \bar{k}_{j}$,

in which

$n_{0}\left(z,\left(H_{j}\right), t\right) \equiv \sum_{j=1}^{j} \tilde{p}_{j} H_{j}^{m_{j}} \bar{N}_{j}, n_{j}\left(z,\left(H_{j}\right), t\right) \equiv(1+r) \tilde{p}_{e j} H_{j}^{m_{j}} \bar{N}_{j}$

Insert (A9) and (A14) in (2)

$N_{i}\left(z,\left(H_{j}\right),\left(\bar{k}_{j}\right), t\right)=n_{0}-\bar{\tau}(\tilde{g}+\bar{g})-$

$$
-\sum_{j=1}^{J}\left(n_{j}+\bar{\tau} \hat{g}_{j}\right) \bar{k}_{j}
$$

in which $\hat{g}_{j} \equiv \tilde{g}_{j}+\bar{g}_{j}$.

Insert (6), (8) and (10) in (21)

From $p_{e j} T_{e j}=\kappa_{j} \bar{y}_{j}$ and (A16), we get

$\sum_{j=1}^{J} \tau_{j} T_{e j} \bar{N}_{j}=\frac{w \tau}{\bar{\tau}}\left(\frac{N_{i}}{\beta_{i}}+\frac{N_{s}}{\beta_{s}}+\frac{N_{e}}{\beta_{e}}\right)$.

From $p_{e j} T_{e j}=\kappa_{j} \bar{y}_{j}$ and (A16), we get 
$\sum_{j=1}^{J} \hat{p}_{e j} \bar{k}_{j}+\hat{p}_{e}=\frac{N_{i}}{\beta_{i}}+\frac{N_{s}}{\beta_{s}}+\frac{N_{e}}{\beta_{e}}$,

where we apply (A7) and

$\hat{p}_{e j} \equiv \frac{(1+r) \bar{p}_{e j}}{w}$,

$\hat{p}_{e} \equiv \sum_{j=1}^{J} \bar{p}_{e j} T_{0} H_{j}^{m_{j}}$,

$\bar{p}_{e j} \equiv \frac{\bar{\tau} \tau_{j} \kappa_{j} \bar{N}_{j}}{\tau p_{e j}}$.

Substitute (A9), (A11) and (A15) into (A17):

$$
\begin{aligned}
\bar{k}_{1} & =\phi\left(z,\left\{\bar{k}_{j}\right\},\left(H_{j}\right), t\right) \equiv \\
& \equiv\left(\bar{n}_{0}-\sum_{j=2}^{J} \phi_{j} \bar{k}_{j}\right) \phi_{1}^{-1},
\end{aligned}
$$

in which

$\phi_{j} \equiv \hat{p}_{e j}+\frac{n_{j}+\bar{\tau} \hat{g}_{j}}{\beta_{i}}-\frac{\bar{\tau} \tilde{g}_{j}}{\beta_{s}}-\frac{\bar{\tau} \bar{g}_{j}}{\beta_{e}}$,

$\bar{n}_{0}=\frac{n_{0}}{\beta_{i}}-\hat{p}_{e}-\frac{\bar{\tau} \hat{g}}{\beta_{i}}+\bar{\tau}\left(\frac{\tilde{g}}{\beta_{s}}+\frac{\bar{g}}{\beta_{e}}\right)$.

We showed that the variables are functions of $\tau,\left\{\bar{k}_{j}\right\},\left(H_{j}\right)$ and $t$ by the procedure in the Lemma. From the procedure, (A15), (17), and (18), we get

$\dot{\bar{k}}_{1}=\bar{\Omega}_{1}\left(\tau,\left\{\bar{k}_{j}\right\},\left(H_{j}\right), t\right) \equiv \lambda_{1} \bar{y}_{1}-\phi,($ A19)

$\dot{\bar{k}}_{j}=\Lambda_{j}\left(\tau,\left\{\bar{k}_{j}\right\},\left(H_{j}\right), t\right) \equiv \lambda_{j} \bar{y}_{j}-\bar{k}_{j}, \quad j=2, \ldots, J$,

$\dot{H}_{j}=\Omega_{j}\left(\tau,\left\{\bar{k}_{j}\right\},\left(H_{j}\right), t\right), j=1, \ldots, J, \quad(\mathrm{~A} 20)$

Take derivatives of equation (A18) in $t$ and then combine the resulted equation with (A18):

$\dot{\bar{k}}_{1}=\frac{\partial \phi}{\partial \tau} \dot{\tau}+\frac{\partial \phi}{\partial t}+\sum_{j=2}^{J} \Lambda_{j} \frac{\partial \phi}{\partial \bar{k}_{j}}+\sum_{j=1}^{J} \Omega_{j} \frac{\partial \phi}{\partial H_{j}}$.

Equal the right-hand sizes of equations (A19) and (A21)

$$
\begin{aligned}
\dot{\tau} & =\Lambda_{1}\left(\tau,\left\{\bar{k}_{j}\right\},\left(H_{j}\right)\right) \equiv \\
& \equiv\left[\bar{\Omega}_{1}-\frac{\partial \phi}{\partial t}-\sum_{j=2}^{J} \Lambda_{j} \frac{\partial \phi}{\partial \bar{k}_{j}}-\sum_{j=1}^{J} \Omega_{j} \frac{\partial \phi}{\partial H_{j}}\right]\left(\frac{\partial \phi}{\partial \tau}\right)^{-1} .
\end{aligned}
$$

We proved the lemma.

\section{References}

Arrow, K.J. (1962) The Economic Implications of Learning by Doing. Review of Economic Studies 29, 155-73.

Arrow K.J. and Debreu, G. (1954) Existence of an Equilibrium for a Competitive Economy. Econometrica 22, 265-90.

Arrow, K.J. and Hahn, F.H. (1971) General Competitive Analysis. San Francisco: HoldenDay, Inc.

Benigno, G. and Benigno, P. (2003) Price Stability in Open Economies. Review of Economic Studies 70, 743-64.

Chatterjee, B. S. and Ravikumar, B. (1992) A Neoclassical Model of Seasonal Fluctuations. Journal of Monetary Economics 29(1), 59-86.

Chiarella, C. and Flaschel, P. (2000). The Dynamics of Keynesian Monetary Growth: Macro Foundations. Cambridge University Press, Cambridge.

Forbes, K. (2000) A Reassessment of the Relationship Between Inequality and Growth. American Economic Review 90, 869-70.

Gabaix, X. (2011) The Granular Origins of Aggregate Fluctuations. Econometrica 79, 733-72.

Gali, J. and Monacelli, T. (2005) Monetary Policy and Exchange Rate Volatility in a Small Open Economy. Review of Economic Studies 72, 707-34.

Gandolfo, G. (2005). Economic Dynamics. Berlin: Springer.

Lorenz, H.W. (1993). Nonlinear Dynamic Economics and Chaotic Motion. SpringerVerlag, Berlin.

Lucas, R.E. (1977) Understanding Business Cycles. Carnegie-Rochester Conference Series on Public Policy 5, 7-29.

Lucas, R.E. (1988) On the Mechanics of Economic Development. Journal of Monetary Economics 22, 3-42. 


\section{Articles}

Mas-Colell, A., Whinston, M.D. and Green, J.R. (1995) Microeconomic Theory. New York: Oxford University Press.

Nolte, D.D. (2015) Introduction to Modern Dynamics: Chaos, Networks, Space and Time. London: Oxford University Press

Obstfeld, M. and Rogoff, K. (1996) Foundations of International Macroeconomics. Mass., Cambridge: MIT Press.

Pasinetti, L.L. (1960) A Mathematical Formulation of the Ricardian System. Review of Economic Studies 27, 78-98.

Puu, T. (2011) Nonlinear Economic Dynamics. Berlin: Springer.

Samuelson, P.A. (1959) A Modern Treatment of the Ricardian Economy: I. The Pricing of Goods and Labor and Land Services. The Quarterly Journal of Economics 73, 1-35.

Shone, R. (2002) Economic Dynamics Phase Diagrams and Their Economic Application. Cambridge University Press, Cambridge.

Solow, R. (1956) A Contribution to the Theory of Growth. Quarterly Journal of Economics 70, 65-94.

Stachurski, j., Venditti, A., Yano, M. (2014) Nonlinear Dynamics in Equilibrium Models: Chaos, Cycles and Indeterminacy. Berlin: Springer.

Stella, A. (2015) Firm Dynamics and the Origins of Aggregate Fluctuations. Journal of
Education, Income, Wealth Inequality and Business

Cycles in a General Equilibrium Growth Model

Economic Dynamics and Control 55 (C), 7188.

Uzawa, H. (1961) On a Two-Sector Model of Economic Growth. Review of Economic Studies 29, 47-70.

Uzawa, H. (1965) Optimal Technical Change in an Aggregative Model of Economic Growth. International Economic Review 6, 18-31.

Walras, L. (1874) Elements of Pure Economics, translated from the French by W. Jaffé, 1954. London: Allen and Unwin.

Zhang, W.B. (1991) Synergetic Economics. Springer-Verlag, Heidelberg.

Zhang, W.B. (2005) Differential Equations, Bifurcations, and Chaos in Economics. Singapore: World Scientific.

Zhang, W.B. (2006) Discrete Dynamical Systems, Bifurcations and Chaos in Economics. Elsevier: Amsterdam.

Zhang, W.B. (2007) Economic Growth with Learning by Producing, Learning by Education, and Learning by Consuming. Interdisciplinary Description of Complex Systems 5, 21-38.

Zhang, W.B. (2016) Impact of Education Subsidies and Taxation on Wealth and Human Capital Accumulation. Eastern European Business and Economics Journal 2(3), 222-47.

Zhang, W.B. (2020) The General Economic Theory: An Integrative Approach. Switzerland: Springer International Publishing. 